\title{
Optical Detonator on the Basis of PETN Dopped with Cobalt Nanoparticles
}

\author{
Anastasia P. Borovikova ${ }^{a}$, \\ Alexander V. Kalenskii ${ }^{a}$ and Alexander A. Zvekov ${ }^{b}$ \\ ${ }^{a}$ Kemerovo State University \\ 6 Krasnaya Str., Kemerovo, 650043, Russia \\ ${ }^{b}$ Federal Research Center of Coal \\ and Coal Chemistry SB RAS \\ 18 Sovetsky, Kemerovo, 650000, Russia
}

Received 29.12.2015, received in revised form 17.02.2016, accepted 16.04.2016

The optical detonator's cup, performing selective sensitivity to laser radiation, was suggested. The cup is based on the secondary explosive PETN, which contains cobalt nanoparticles. The optimal nanoparticles' size was estimated using hot-spot model of laser initiation. The critical energy density for the suggested explosive composition for the cup was determined experimentally.

Keywords: PETN, cobalt nanoparticles, optical detonator, laser initiation.

DOI: $10.17516 / 1998-2836-2016-9-2-152-158$.

C) Siberian Federal University. All rights reserved

* Corresponding author E-mail address: kriger@kemsu.ru 


\title{
Оптический детонатор \\ на основе ТЭНа, допированного \\ наночастицами кобальта
}

\author{
А.П. Боровикова \\ А.В. Каленский ${ }^{\mathbf{a}}$, А.А. Звеков \\ ${ }^{a}$ Кемеровский государственный университет \\ Россия, 650043, Кемерово, ул. Красная, 6 \\ ${ }^{6}$ Федеральный исследовательский центр \\ угля и углехимии СО РАН \\ Россия, 650000, Кемерово, пр. Советский, 18
}

Предложен капсюль оптического детонатора с селективной чувствительностью к лазерному воздействию. Капсюль основан на вторичном взрывчатом веществе ТЭНе, допированном наночастичами кобальта. Оптимальные размеры наночастии были оценены в рамках микроочаговой модели инициирования теплового взрыва. Измерена критическая плотность энергии лазерного инициирования разработанного состава для детонатора.

Ключевые слова: ТЭН, наночастицы кобальта, оптический детонатор, лазерное инициирование.

\section{Introduction}

The mining technologies used in Russia now can lead to accidental explosions due to an unauthorized operation of the electric detonators. Thus the more reliable new detonators having enhanced sensitivity to a definite action type are required. The best way to make stripping and tunneling works safer is to use optical detonators [1]. Traditionally they are based on the primary explosives [2-4], which are not safe for storage, and lose their properties at elevated temperature. In order to produce an optical detonator on the basis of secondary explosives it is necessary to significantly increase their sensitivity to the laser action. One of the main directions of the optical detonators' cup improvement is doping the secondary explosives with light-absorbing particles [5].

The initiating thresholds of pentaerythritol tetranitrate (PETN) containing aluminum nanoparticles for the first and second harmonics of Nd:YAG laser was studied in [6-11]. Sensitivity of this material to the laser action is about $0.5 \mathrm{~J} / \mathrm{cm}^{2}$ (sensitivity increases more than in 100 times comparing to undoped samples) while the threshold of shock initiation does not change. So secondary explosives doped with the metal nanoparticles might be used in a cup of optical initiating systems.

The goal of this work is to study the possibility of optical detonator based on the PETN pressed pellet doped with cobalt nanoparticles with mass concentration $0.1 \%$ creation. 


\section{Experimental section and results}

The PETN powder with particles' sizes 1-2 $\mu \mathrm{m}$ and the powder of cobalt with particles' radii 100$120 \mathrm{~nm}$ were used to prepare pellets. Mechanical mixture of the powders was ultrasonificated to obtain uniform distribution of the dopant inside the sample (as in $[6,7]$ ). Then a hitch was pressed during 30 minutes at the maximal pressure $1.8 \mathrm{GPa}$ and the pellet with density value close to the single crystals' one was obtained. The pellets' parameters are: diameter $3 \mathrm{~mm}$, thickness $1 \mathrm{~mm}$ and density $(1.73 \pm$ $0.03) \mathrm{g} / \mathrm{cm}^{3}$.

The composite is optimal to use in optical detonator if the mass concentration of the cobalt nanoparticles is $0.1 \%$, because both the bigger and the smaller amount of the metal makes the initiation threshold increase. The first harmonics of the Nd:YAG laser (wavelength $1064 \mathrm{~nm}$, pulse duration full width at half maximum $14 \mathrm{~ns}$ [2-7]) for initiation was used.

Fig. 1 displays the diagram of the detonator cup. As seen, it consists of a metal sheath (1) and a pellet of the pressed photosensitive composite explosive inside the sheath (2). The metal sheath with inner diameter $3 \mathrm{~mm}$ is made of aluminum, the wall thickness is $0.08 \mathrm{~mm}$. The sheath also has a transparent shield (3) made of optical glass (thickness is $900 \mu \mathrm{m}$ ). Explosion is initiated by the laser pulse (4).

Explosive decomposition of the composite initiated by the first harmonics of Nd:YAG laser was observed through the optical shield if the energy density was above $\sim 1.7 \mathrm{~J} / \mathrm{cm}^{2}$. This value is more than one order of magnitude less than that for the pure PETN $\left(\sim 100 \mathrm{~J} / \mathrm{cm}^{2}\right)$. The initiation threshold for the other types of action keeps at the level of pure PETN. Hence we have achieved the necessary selective sensitivity.

\section{Simulation methods and results}

Radius of the metal particles, which provides the minimal critical initiation energy, has been determined both experimentally and theoretically. Theoretical study was based on the calculation of the metal nanoparticles absorption factor in a transparent media and reaction initiation kinetics. The last one was simulated considering thermal conduction inside the metal and PETN as well as PETN exothermic decomposition obeying a simple first-order reaction. The equation system describing the release and transfer of heat in the system nanoparticle - PETN matrix is as follows [7-17]:

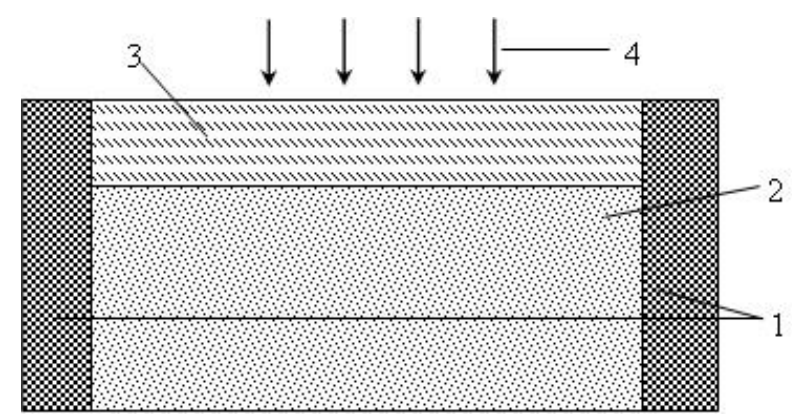

Fig. 1. Sketch of the detonator cup. 1 is a metal sheath, 2 is a pellet of the pressed photosensitive composite explosive, 3 is a transparent shield and 4 is laser pulse 


$$
\begin{aligned}
& \frac{\partial T}{\partial t}=\alpha_{M}\left(\frac{\partial^{2} T}{\partial x^{2}}+\frac{2}{x} \frac{\partial T}{\partial x}\right), x<R, \\
& \frac{\partial T}{\partial t}=\alpha\left(\frac{\partial^{2} T}{\partial x^{2}}+\frac{2}{x} \frac{\partial T}{\partial x}\right)+k_{0} \frac{n Q_{t}}{c} \exp \left(-\frac{E}{k_{B} T}\right), x>R, \\
& \frac{\partial n}{\partial t}=-k_{0} n \exp \left(-\frac{E}{k_{B} T}\right), x>R,
\end{aligned}
$$

where $T$ is temperature, $E=165 \mathrm{~kJ} /(\mathrm{mol} \cdot \mathrm{K})$ is activation energy of decomposition, $k_{0}=1.2 \cdot 10^{16} \mathrm{~s}^{1}$ is pre-exponential factor, $Q_{t}=9.64 \mathrm{~kJ} / \mathrm{cm}^{3}$ is the heat of reaction, $a=1.1 \cdot 10^{3} \mathrm{~cm}^{2} \mathrm{~s}^{1}$ and $\alpha_{M}=0.267 \mathrm{~cm}^{2} \mathrm{~s}^{1}$ are thermal diffusivities of PETN and cobalt correspondingly, $c=2.22 \mathrm{~J} / \mathrm{cm}^{3} \mathrm{~K}$ is volumetric heat capacity of PETN, $R$ is radius of inclusion, $n$ is relative concentration of PETN, $x$ and $t$ are spatial coordinate and time, respectively, $k_{B}$ is Boltzmann constant. The initial conditions were $T=T_{0}$, where $T_{0}=300 \mathrm{~K}$, for the temperature and $n=1(x>R)$ for the relative concentration of PETN. The range of particles' radii of 20-120 nm was studied in order to elucidate the optimal sizes of the particles for the PETN-cobalt composite in case of initiation by the first harmonics of Nd:YAG laser influence. Radiation is absorbed on the inclusion-matrix border, so the boundary condition is:

$$
\frac{J(t)}{4 \pi R^{2}}-\left.c_{M} \alpha_{M} \frac{\partial T}{\partial x}\right|_{x \rightarrow R-0}+\left.c \alpha \frac{\partial T}{\partial x}\right|_{x \rightarrow R+0}=0,
$$

where $c_{M}=3.74 \mathrm{~J} / \mathrm{cm}^{3} \mathrm{~K}$ is volumetric heat capacity of cobalt, $J(t)$ is absorbed laser power density. The parameters used were based on the data represented in [7-17]. The time dependence of the laser power density is close to the function of the normal distribution [18]. If the time reference point coincides with the maximum of the laser pulse power [2-4, 16-19],

$$
J(t)=\sqrt{\pi} Q_{a b s} R^{2} k_{i} H \exp \left(-k_{i}^{2} t^{2}\right),
$$

where $k_{i}=1.1894 \cdot 10^{8} \mathrm{~s}^{-1}$ is the parameter of the pulse duration (corresponds to pulse duration on halfheight $14 \mathrm{~nm}), Q_{a b s}$ is the efficiency factor of absorption that depends on the inclusion's radius, $H$ is pulse energy density. The boundary condition of the first kind on the calculation area outer boundary was used [19]. The method of $Q_{a b s}$ calculation is described earlier [14]. The complex refractive index is the main parameter influencing the $Q_{a b s}(R)$. It depends on particles' material and equal to $m_{i}=3.7505$ 5.4647i [19] for cobalt at the wavelength $1064 \mathrm{~nm}$.

Dependence of absorption factor (wavelength $1064 \mathrm{~nm}$ ) on the cobalt particle's size in PETN has maximum with coordinates $R_{\max }=97.2 \mathrm{~nm}, Q_{a b s \max }=1.269$. For the smaller radii the curve tends to zero, and the Rayleigh law in the limit $R \rightarrow 0$ is applicable. In the range of large radii of the cobalt nanoparticles the dependence on $R$ is weak, since there are a lot of oscillations with comparable intensity so their sum varies insufficiently.

Method of the critical energy density determination was described in [7-14, 16-17]. The calculation results are shown on the Fig. 2. The critical energy density is minimal for nanoparticles with radius $93 \mathrm{~nm}$. The optimal radius is close to the maximum abscissa on the absorption efficiency dependence. It means that the optical properties plays more significant part than thermophysical ones in terms of 


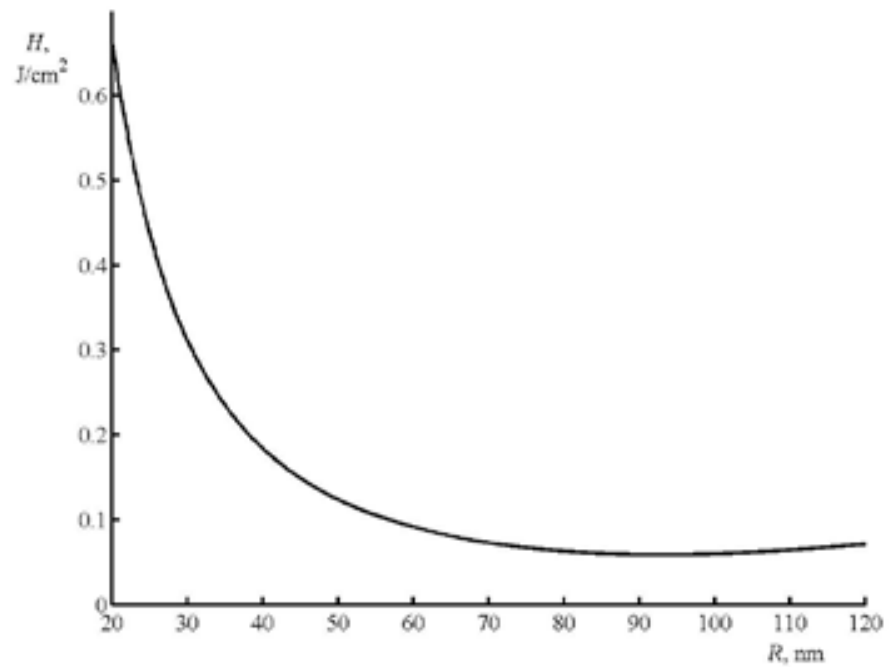

Fig. 2. The calculated dependence of the laser initiation critical energy density on the radius of cobalt nanoparticles

the model. Thus the optimization of an optic detonator has to include: (i) the explosive preparation containing the nanoparticles with optimal sizes and (ii) optimization of the cup geometry.

The calculated values of critical laser pulse energy density are about 26 times less than the experimental ones. There could be a number of reasons. The model does not take into account the energy consuming phase transitions that are able to significantly diminish the hot-spot temperature making the threshold energy density rise. The oxide layer on the nanoparticle's surface is an obstacle also for the self-sustaining reaction launching. The reaction kinetic parameters are extrapolated from the moderate temperature region while this extrapolation is questionable. The decomposition of secondary explosives typically contains lots of stages so the limiting stage changing with subsequent reaction rate decreasing is quite possible. At the same time, the process is ruled by the laser radiation absorption mostly. For that reason, the micro hot-spot model seems to be accurate enough to estimate the optimal radius value which is essential on the way of optical detonator cup development.

\section{Resume}

The construction of an optical detonator cup and the appropriate explosive substance containing PETN and cobalt nanoparticles for its filling were described. The model of laser initiation of this energetic material was analyzed. The optimal nanoparticle's radius was estimated as $93 \mathrm{~nm}$ and the corresponding minimal critical initiation energy density of the laser pulse was calculated. It was shown that the suggested energetic material keeps its performance on the level of pure PETN while its sensitivity to laser irradiation is significantly improved being estimated experimentally as $1.7 \mathrm{~J} / \mathrm{cm}^{2}$.

This work was supported by Ministry of Education and Science of the Russian Federation (governmental project No. 2014/64), grant of the Russian Federation President (MK-4331.2015.2) and Russian Foundation for Basic Research for the financial support (grant 14-03-31648). 


\section{References}

1. Volkova A.A., Zinchenko A.D., Sanin I.V. et al Time characteristics of laser initiation of PETN. Combustion, Explosion and Shock Waves. 1977. Vol. 13(5), P. 645-650. 10.1007/BF00742225.

2. Zhuravlev Yu.N., Lisitsyn V.M. A study of the reactivity of silver azide based on calculations of the band properties within the framework of density functional theory. Russian Journal of Physical Chemistry B. 2014. Vol. 8(2), P. 117-125. 10.1134/S1990793114020109.

3. Borovikova A.P., Kalenskii A.V., Zykov I.U. Calculation of the chemical reaction front width in solids. Aspirant. 2015. Vol. (2), P. 38-41.

4. Kalenskii A.V., Ananyeva M.V., Borovikova A.P., Zvekov A.A. Probability of generation of Frenkel defects in the decomposition of silver azide. Russian Journal of Physical Chemistry B. 2015. Vol. 9(2), P. 163-168. 10.1134/S1990793115020062.

5. Ioffe V.B., Dolgolaptev A.V., Aleksandrov V.E., Obrazcov A.P. The ignition of the aluminumcontaining condensed systems by monopulse laser radiation. Combustion, Explosion, and Shock Waves. 1985. Vol. 21(3), P. 316-320.

6. Aduev B.P., Nurmukhametov D.R. The influence of added aluminum nanoparticles on the sensitivity of pentaerythritol tetranitrate to laser irradiation. Russian Journal of Physical Chemistry B. 2011. Vol. 5(2), P. 290-292. 10.1134/S1990793111020163.

7. Kalenskii A.V., Anan'eva M.V., Zykov I.Y. et al Influence of laser wavelength on the critical energy density for initiation of energetic materials. Combustion, Explosion, and Shock Waves. 2014. Vol. 50(3), P. 333-338. 10.1134/S0010508214030113.

8. Ivashenko G.Jk. T Kinetics of formation of foci of explosive decomposition of PETN composites - Ni. Modern fundamental and applied researches. 2015. Vol. 3(18), P. 33-40.

9. Galkina E.V., Radchenko K.A. The model of initiation of composites PENT - Tin by the pulse ND: YAG laser. Nauka-Rastudent.ru. 2015. Vol. 9, P. 12.

10. Radchenko K.A. The critical density regularities of initiation explosive decomposition PETN-V by neodymium laser with the $12 \mathrm{~ns}$ duration. Modern fundamental and applied researches. 2015. Vol. 3(18), P. 40-46.

11. Zykov I.Yu. The critical initiation energy density of PETN with aluminum nanoparticle additives. Modern fundamental and applied researches. 2013. Vol. 1(8), P. 79-84.

12. Aduev B.P., Nurmukhametov D.R., Furega R.I., Liskov I.Y. Light absorption by formulations based on petn and aluminum nanoparticles during pulsed laser irradiation. Russian Journal of Physical Chemistry B. 2014. Vol. 8(6), P. 852-855. 10.1134/S1990793114110128.

13. Kriger V.G., Kalenskii A.V., Zykov I.Y. et al. Heat-transfer processes upon laser heating of inert-matrix-hosted inclusions. Thermophysics and aeromechanics. 2013. Vol. 8(6), P. 367-374. 10.1134/ S0869864313030153.

14. Tarzhanov V.I., Litvinov B.V., Zinchenco A.D. et al. Laser initiation of explosives. Increasing the safety of blasting technology. Izvestia Vuzov. Gorny zhurnal. 1999. Vol. 9-10, P. 94-98.

15. Kozlenko E.A. The formation of the center of explosive decomposition of composites PENT aluminum pulse neodymium laser. Aspirant. 2015. Vol. 9, P. 48-51.

16. Nikitin A.P. Calculation of critical parameters of explosive decomposition of PETN's samples containing chrome nanoparticles. Modern fundamental and applied researches. 2013. Vol. 2(9), P. 2934. 
17. Odincova O.V. Initiation of the PETN-silver composites by the first and the second harmonics of the Nd:YAG laser. Aspirant. 2015. Vol. 4(9), P. 50-54.

18. Odincova O.V., Ivaschenko G.E. The temporal pulse shape of the first harmonic of a neodymium laser. Modern fundamental and applied researches. 2015. Vol. 2(17), P. 43-48.

19. Ananyeva M.V., Kalenskii A.V., Zvekov A.A. et al. The optical properties of the cobalt nanoparticles in the transparent condensed matrices. Nanosystems: Phys. Chem. Math. 2015. Vol. 6(5), P. 628-636. 10.17586/2220-8054-2015-6-5-628-636. 